\title{
Leveraging Organizational Performance through Effective Mission Statement
}

\author{
Ekpe Oyono Ekpe ${ }^{1}$, Sunday Isaac Eneh ${ }^{1} \&$ Benjamin J. Inyang ${ }^{1}$ \\ ${ }^{1}$ Department of Business Management, University of Calabar, Calabar, Nigeria \\ Correspondence: Benjamin J. Inyang, Department of Business Management, University of Calabar, Calabar, \\ Nigeria. E-mail: benji1955.unical@yahoo.co.uk
}

Received: July 5, 2015

Accepted: August 8, 2015

Online Published: August 25, 2015

doi:10.5539/ ibr.v8n9p135

URL: http://dx.doi.org/10.5539/ ibr.v8n9p135

\begin{abstract}
The mission statement is a critical and an integral part of the organization as an entity and the operating plan, which has become a unique vehicle through which the organization in the business world, articulates it strategic intent to exist, survive, grow and how it relates with stakeholders around it and including the wider society. The important question to ask is whether or not the existence of a mission statement is associated with or influences organizational performance? The findings from the various studies which explored this relationship appear rather inconclusive. Adopting a qualitative research approach, this study critically explored the essential link between a mission statement and organizational performance. The study established that the potential power of an effective mission statement in leveraging organizational performance was derived mainly from the fact that a mission statement is the starting point of the organization's entire planning process, which serves as the basis for the formulation of objectives and strategies appropriate to the organization's overall purpose and legitimate its existence. The study proposed that organization should strive to improve its mission statement as well as communicate same effectively to create mutual expectations among stakeholders.
\end{abstract}

Keywords: mission statement, vision, strategic intent, organizational performance

\section{Introduction}

Organization relates its existence and survival to a unique reason and purpose. This uniqueness is reflecting in the mission statement of the organization. Mission statements have increasingly become popular strategic managerial tools among organizations in explaining their respective business missions and purposes clearly to the society. This is due to the needs of organizations to develop realistic business objectives and strategies that can be achieved within their capacity. A mission statement was earlier considered as the scope of a business activities a firm pursues. The definition of mission has gradually expanded to represent a concept that embodies the purpose of existence of an organization.

A mission statement is a developed document that defines the goals of a stable and unique organization. It defines the purpose of the organization, and act as a medium that guides people within the organization so that they can work independently as well as collectively to achieve the desired level of the organizational performance (Kotler, Armstrong, Saunders, \& Wong, 2008). According to Bart (1998) a mission statement is an enduring statement of purpose that reveals an organization's product or services, customers and philosophy. To create this enduring purpose, the first step typically requires that organization asks itself some difficult questions, such as "why do we exist?" and "what is our purpose?" When these questions are thoughtfully answered, the resultant document is generally expected to provide a more focused guide for decision-making, allocation of resources and to motivate and inspire employees (Bart \& Hupfer, 2004).

Forbes and Seena (2006) have demonstrated that a mission statement is not just a concept, but also a package that includes some components such as financial goals, geographical domain and competitive advantage. Today, managers consider mission statement as one of the important managerial tools which has the power of directing the behaviour in organization. They are of the opinion that it gives focus and encourage strategy implementation, improves organizational climate, internal and external communication and improves management and leadership in a company (Macedo, 2009).

The potential power of a meaningful mission statement in enhancing organization's performance is derived mainly 
from the fact that the mission statement gives a sense of purpose and direction to the organization and legitimates its existence (Analoui \& Karami, 2002). However, the importance of developing mission statement and its widespread application is not clear to organization. There is no consensus about mission statements and its components and characteristics, each researcher according to his ideas, has assigned components and special features to mission statement (Mohammed \& Mojtabas, 2013). According to Bart (1998) researchers have focus more on content analysis and characteristics of mission statement and as a result there is a little experimental knowledge on effectiveness, overall advantage, as well as understanding the relationship between mission statement and organizational performance.

In this paper we will first define mission statement and its expected role in an organization, and then we will review literature pertaining to the relationship between mission statement and organizational performance. We conclude by discussing the specific findings and also suggest how the results could be applied more generally.

\section{Literature Review}

\subsection{The Concept of Mission Statement}

Organizational mission is an organization's reasons for existence. A mission statement is the broad definition of the organization's mission, a brief and formalized document intended to distil an organization's purpose and function. A mission statement reflects what the current managers, directors and owners of firms believe the organization is and where it is likely to be headed (Desmidt \& Prinzle, 2007). It is a starting point for constancy of purpose, because it attempts to align organizational processes with business strategies.

Mission statement answers basic questions stakeholders might ask about an organization: Why do we exist? What is our purpose? What do we want to achieve? (Falsey, 1989). It defines the scope of organization operations and distinguishes the organization from similar one (David, 1993). It indicates the basic thrust of activity areas of the firm including its products, services, business and market and even technology (Inyang, 2004). Drucker (1971) links mission statement to business objective and defines it as a precursor to clear and realistic business objectives.

Even though strategic management distinguishes between vision and mission statement, many organizations confuse them and put them together in the same statement (Sufi \& Lyons, 2003). An organization's vision statement may describe desirable and possible future state or long term aims of an organization and is also a backdrop of a purpose and organization's strategy, it affects key priorities and behavioral standards in the organization. So it seems that beside the key priorities, a mission statement may address values and beliefs as well (Ireland \& Hitt, 1992). Organizational values, which are often included in a vision or mission statement (Hussey, 1998), are small sets of general and guiding principles that are not to be confused with the specific cultural or operating practices (Sufi \& Lyons, 2003).

Horwath (2005) sees a vision as providing a mental picture of inspirational existence that an organization is striking or working toward. Albrecht (2006) considers a vision statement as an image of what the members or people in an organization aspire for or to become. The vision aligns people in activities that cut across the different level in organization and this facilities goal setting and planning. Horwath (2005) further notes that, jointly used, mission, vision, and values provide a powerful directional force for unifying and co-ordinating organizational actions, operations, and decisions to ensure the optimal use of resources.

An effective mission statement inspires employees and provides a focus and direction for setting lower level objectives. Ganu (2013) defines organization's mission as a set of value, beliefs and norms of behaviour shared by its (a firm's) members that influence employees' preference and behaviour. Analoui and Karami (2002) note that a mission statement promotes a sense of share expectations among employees and communicate a public image of the firm to important stakeholders.

Thus, the mission communicates not merely the future desirable stage of a firm, rather it explicitly expresses the long embedded corporate identity, corporate purpose and strategic intent in a very succinct form. It is the "cultural glue" which ensures unanimity of purpose in an organization across all levels and generation of the firm's employee. A mission statement therefore sets the boundaries for how resources should be allocated and what strategic and operational goal should be set. Sufi and Lyons (2003) note that a mission statement is made effective and real only when it affects the behaviour and guides the people's action.

\subsection{The Role of Mission Statement in an Organization}

Mission statement is an integral part of organization plans for both public and private organizations. Today many modern organizations draft a formal documents that bears what is their mission statements or their equivalents. Specifically, for organizations with profit motive, the mission statements constitute their preambles of what they want to achieve and operating plans. 
It has become generally accepted over the years by both academics and practitioners that a vital starting points for strategic considerations is the formulation of a mission statement for the future. Pearce (1982) states that a mission statement can serve as a valuable tool in directing the formulation and implementation of strategy. He argues that it can lead to a heightened sense of purpose in addressing the issues of why the organization exist and whom it serves. Klemm, Sanderson, and Luffman (1991) state that there are two views regarding the purpose of such statement: first, to enhance the organization's image externally and second to motivate employees.

Mission statement can have a goal-setting effect when it specifies the goals of the firms and makes it easier for employees to make daily decisions (Mullane, 2002). Mission statement has a coordination effect when it reduces communication costs and facilitates coordination among employees (Biloslavo \& Lynn, 2007). Managers perceive mission statement as one of the most important managerial tool which has the power of directing behavior and sets the boundaries for how resources should be allocated and what strategic and operational goals should be set. A mission statement acknowledges the organization's strength and then inform employees where to direct their effort in order to take advantage of those strength. According to Drucker (1971) organization is not defined by its name or its statue, but is defined by its mission. He argues that only a clear definition of the mission and purpose of the organization which made it possible to achieve realistic goals and influence on its success or failure. William (2008) lists numerous roles of such effective mission statement in an organization's present and future situation. Some mission statement roles related to e.g. strategic implementation, internal and external communication, management and leadership, and organizational climate influence. The model below in Figure 1 shows the strategic role of an effective mission statement.

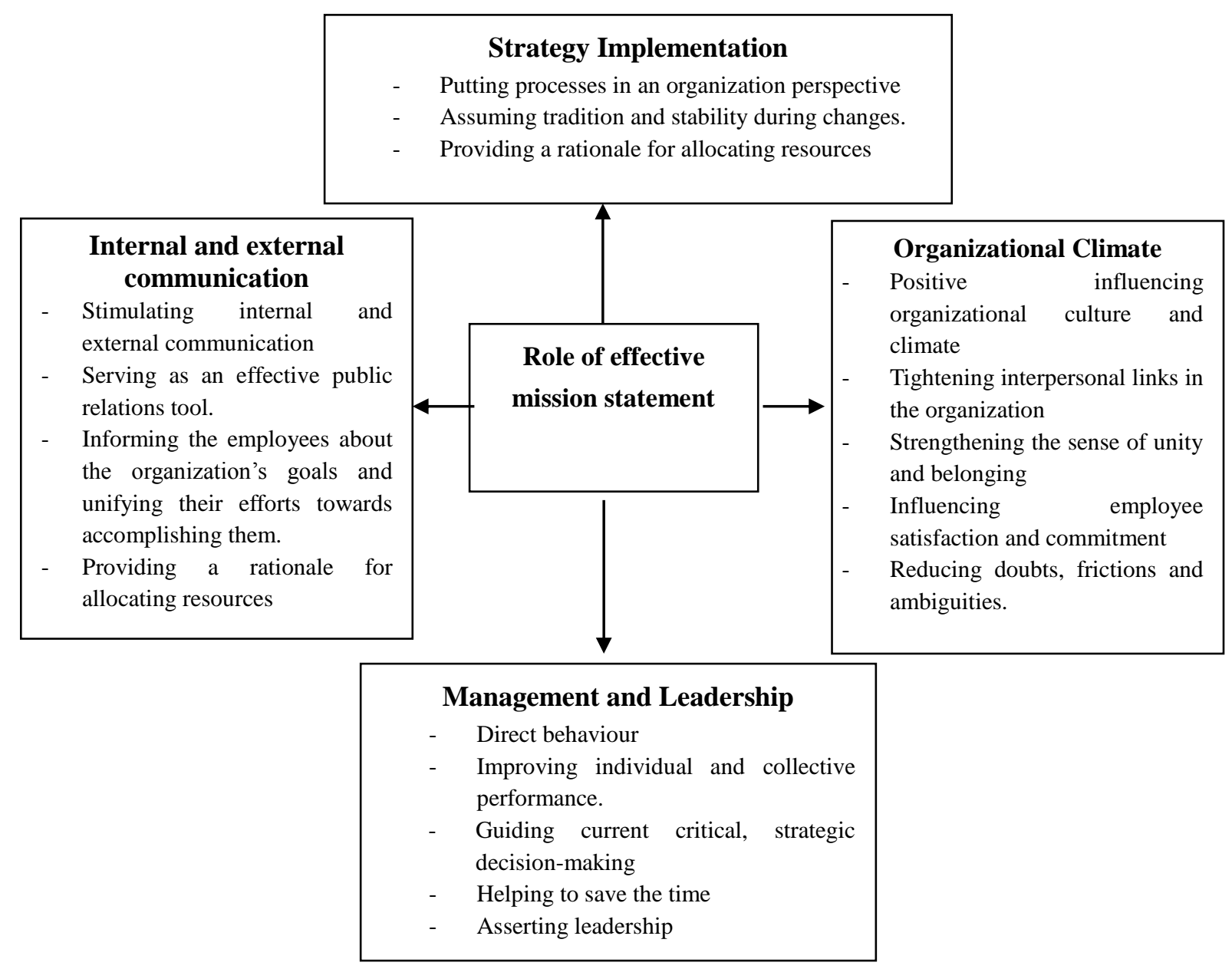

Figure 1. A conceptual model for a strategic role of effective mission statement 


\section{Mission Statement and Organizational Performance}

Studies investigating the relationship between mission statement and organization's performance are rare and their findings in most case not very conclusive (Peyrefitte \& David, 2006; Bart \& Baetz, 1998; Bart, Bontis, \& Taggar, 2001). This is because there is no direct agreement among scholars on what constitutes an effective mission statement in business organizations. However, extracting from different scholars and models one can come up with several components that are largely attributed to the effectiveness of a mission statement in business (David, 1989). The existing theoretical assumptions take attribute that constitute an effective mission statement as characteristics features that can help business realize their core objectives including growth and profitability (high performance). The most commonly identified components of what constitute a sound mission statement include having a concern for employees, defining clearly who are the customers, and focus on survival, growth and profitability of the business. A sound mission statement must also consider and address public image concerns of an organization, clearly address the core management philosophy, define what the organization is and distinguish it from all others, anticipate customers' needs and ensure commitment to addressing them (Desmidt \& Heene, 2005). Thus, it is imperative that an effective mission statement plays a linking role between the business, employees and the customers.

A major shortcoming of the mission statement literature is the contradictory empirical evidence which fail to support the linking role between mission statement and organizational performance. William (2008) noted that very little is known empirically about the actual (as opposed to the perceived) effectiveness, overall usefulness and performance relationship of mission statement. While the majority of published literature on mission statement tends to extol the benefits of well-articulated and executed mission statements and its relationship with organization performance, there are those scholars who argue against the value and effectiveness of a mission statement to organizational performance (David, 1989, Leonard, 2001; Ireland \& Hitt, 1992; Klemm, Sanderson, \& Luffman, 1991). For example, David (1989) in his study conducted on "How companies define their mission", did not find any correlation between performance and mission statement presence neither did Klemm et al., (1991). Leonard (2000), Ireland and Hitt (1992) argue that the problem with most mission statements is that they are "paper tiger", a mere "slogan", suffering from being too vague, having involved too few stakeholders, being too replete with hollow platitudes. Alternatively, a few scholars (Pearce \& David, 1987; Rarick \& Vitton, 1995; Stone \& Brush 1996; Falsey, 1989) have empirical support that mission statements are valuable and contribute to higher profitability.

Campbell (1993) reports a positive relationship between mission statement presence and organizational performance as did Medley (1992) and Wilson (1992) who claimed that the presence of mission statement can result in a 50\% increase in organizational effectiveness. Gharleghi, Nikbakht, and Bahor (2011) found that flexibility of mission statement had most impact on the organizational performance and the perfectness of the mission statement had the least impact on organizational performance. Oghojafor, Olayemi, and Okonji (2011) argue that the use of mission statements is not only a mere "slogans" but help to open the employees' eyes to see their daily tasks and roles and the vision and mission so as to attain business objective. Rarick and Vitton (1995) concluded that having a mission statement significantly increases shareholders equity and organizational performance.

Nevertheless, when one take both sides of the findings into consideration, one finds that there is ample evidence of some agreement that mission statement affect organizational operations and managerial aspects despite these relationship being contested in some quarters. One logical assumption that emerges from this paradox is that the conclusions may also be subjected to the business context in which an organization works. Therefore a more contextual analysis of the relationship between mission statement and organizational performance is of great importance.

Effective mission statement determines the organizational goals and direction, organizational existence and provides strategy plan content for the organizational development and successful implementation. It can be viewed as a communication instrument as they are clearly written with a view not only to the expression of something fundamental about the organization, but with a view to achieving it as well. David (2007) argues that effective mission statement must be broad in scope, generate strategic alternatives, not overly specific, reconcile diverse interest of different stakeholders, arouse positive feelings and emotions among stakeholders, motivate readers to action and must generate favourable impression of the organization. Bart (2007) notes that a mission statement is the starting point of the organization entire planning process. The starting point serves as the basic for development of goals, objectives and strategies appropriate to the organization's overall purpose. In turn, the mission-derived goals are intended to inform operational decisions regarding resources allocation, organizational structure and programming. 
Weiss and Piderit (1999) argue that organization mission statement has important significance to firm's performance in that it has incentive for employees to work hard. Mission statement makes organizational members inside and outside to constantly examine, reflect and consider organization situation and task effectively. Campbell (1993) maintains that mission statement serves as a tool in defining an organizational culture that is attractive to employees, potentially affecting employee recruitment, job satisfaction, motivation and retention.

\section{Methodology}

This is a qualitative research approach based solely on insights drawn from the analysis of the existing literature of different studies, and books related to the topic of study in order to investigate the relationship between mission statement and organizational performance. This research work will serve as a means to help acquire useful information or knowledge about the subject area. By drawing on the existing literature, not only the topic under consideration is theorized, but also formulates and discusses the proposition that will help illuminate and discuss some ways for organizations to understand the relationship between mission statement and organizational performance. As posited by Gummesson (2002), one burdensome task with all research is not to collect or rather generate more data, but to interpret and combine what is already there and make some sense out of it. We submit to this assertion and try to make the most out of the insights we can get from the existing literature to address the phenomenon under study.

\section{Discussion}

A mission statement is positively related with organizational performance. This result is mainly basic on organization operating plans and decision-making guiding functions of mission statements. As the starting point of organizational strategic planning, mission statement instructs the organizational direction, internal decision-making and resource allocation. As a knowledge platform and information tool, a mission statement passes on the organizational value and philosophy. In addition to direct role in organizational performance, a mission statement can guide the top management for better performance.

In this case, managers who already work longer in the organization should have a better understanding of the mission statement and it should be their responsibility to show examples of good work ethic and behaviour to the others. The employees of the organization could achieve its mission, execute its strategy and generate important business result through clear mission statement. This could influence performance through communication, leadership, organizational climate and strategy implementation.

The study suggested that organization should continue to strive to improve on its mission statement as well as communicating same to create mutual expectation among stakeholders. The study also suggested that a mission statement is necessary for the employee, customers and other stakeholders to understand the organization's direction. Without it, they are unable to make sense of their being and existence in the organization. The study further suggested that mission statement should be developed based on realities of organizations, and what currently is available, not based on what the organization is trying to achieve in the future.

\section{Conclusion}

The purpose of this study is to advance understanding on the relationship between mission statement and organizational performance. Mission statements have increasingly become popular management tools among organizations in explaining their respective business mission and purpose clearly. This popularity is mainly due to the needs of organizations to develop and articulate their strategic intent to exist, survive, and grow and how they should relate with actors around them including market, businesses, employees and even the wider society to achieve higher performance.

Mission statement communicates much about the aims, aspirations and values of organizations and units of organization. It represents the confluence of culture, purpose, values, leadership, and a host of tangible and intangible resources collectively and integratively targeted toward enhanced performance. In this era of heightened expectations and continuous improvement, firms are constantly seeking alternative means of enhancement. Mission statements offer a glimpse of the priorities of organizations and a window to view behaviour leading to various levels of performance.

Effective mission statements give organization a focus and a strategy for the future. They provide a sense of direction and purpose. In times of change and growth they can be an anchor and a guide in decision making. Defining an organization by what it produces and who it satisfies are major steps towards creating a sound and stable mission statement, capable of enhancing organisation's ability to achieve competitive advantage 


\section{Acknowledgements}

This paper was presented at the 2015 International Business \& Education Conferences organized by The Clute Institute of USA, held at Kensington Close Hotel, London, UK on $7^{\text {th }}-11^{\text {th }}$ June, 2015. The authors are grateful to two anonymous reviewers for their comments and the conferences' participants for their valuable inputs.

\section{References}

Albrecht, I. L. (2006). The northbound train. Chapter 9: Model building 102: Vision, mission, and values. New York: America Books.

Analoui, F., \& Karami, A. (2002). CEOs and development of the meaningful mission statement. Corporate Governance, 2(3), 13-20. http://dx.doi.org/10.1108/14720700210440044

Bark, C. K., \& Baetz, M. C. (1998). The relationship between mission statements and firm performance: An exploratory study. The Journal of Management Studies, 36(6), 823-853. http://dx.doi.org/10.1111/1467-6486.00121

Bart, C. A. (2007). A comparative analysis of mission statement content in secular and faith-based hospital. Journal of Intellectual Capital, 8(4), 682-694. http://dx.doi.org/10.1108/14691930710830837

Bart, C. K. (1998). Comparison of mission statements and their rationales in innovative and non-innovative firms. $\begin{array}{lllll}\text { International Journal of Technology } & \text { Management, } & 16(2), & 64-77 .\end{array}$ http://dx.doi.org/10.1504/IJTM.1998.002645

Bart, C. K. (1998). Mission matters. The CPA Journal, 68(6), 56-57.

Bart, C. K., \& Hupfer, M. (2004). Mission statements in Canadian Hospitals. Journal of Health Organization and Management, 18(2), 92-110. http://dx.doi.org/10.1108/14777260410538889

Bart, C. K., Bontis, N., \& Taggar, S. (2001). A model of the impact of mission statements on firms' performance. Management Decision, 39(1), 19-35. http://dx.doi.org/10.1108/EUM0000000005404

Biloslavo, R., \& Lynn, M. (2007). Mission statements in Slovene enterprises: Institutional pressures and $\begin{array}{llll}\text { contextual } \quad \text { Management } & \text { 773-788. }\end{array}$ http://dx.doi.org/10.1108/00251740710746024

Campbell, A. (1993). The power of mission: Aligning strategy and culture. Planning Review, 20(5), 10-13. http://dx.doi.org/10.1108/e6054369

David, F. R. (1989). How companies define their mission. Long Range Planning, 22(1), 90-97. http://dx.doi.org/10.1016/0024-6301(89)90055-1

David, F. R. (1993). Strategic management. New York, NY: Macmillan Publishing.

David, F. R. (2007). Strategic management: Cases and practices. New York: McGraw-Hill Co Inc.

Desmidt, S., \& Heene. (2005). Mission statements: In search for ameliorated performance through organization-employee value congruence. Retrieved from http://www.law.kuleuven.be/line/integriteit/egpa/previous-egpa-conferences/Lisbon-2003/desmidt-pdf

Desmidt, S., \& Prinzle, A. A. (2007). The impact of mission statements: An empirical analysis from a sense making perspective. Retrieved from http://www.highbeam.com/doc/IGI-218876952.hmtl

Drucker, P. (1971). Management. Oxford: Butterworth-Heinemann.

Falsey, T. A. (1989). Corporate philosophies and mission statements: A survey and guide for corporate communicators and management. Westport, CT: Greenwood.

Forbes, D. J., \& Seena, S. (2006). The value of a mission statement in an association of not-for-profit hospitals. International Journal of Healthcare Quality Assurance, 19(5), 409-419. http://dx.doi.org/10.1108/09526860610680058

Ganu, J. (2013). Institutional mission statements and attitudinal outcomes of selected faith-base tertiary institution in Ghana. Journal of Applied Business and Economics, 14(2), 20-30.

Gharleghi, E., Nikbakht, F., \& Bahar, G. (2011). A survey of the relationship between the characteristics of mission statement and organizational performance. Research Journal of Business Management, 5(3), 117-124. http://dx.doi.org/10.3923/rjbm.2011.117.124

Gummesson, E. (2002). Total relationship marketing: Marketing management, relationship strategy and CRM approaches for the network economy (2nd ed.). Oxford: Heinemann. 
Horwarth, R. (2005). Discovering purpose: Developing mission, vision, and values. Strategic Thinking Institute. Retrieved from http://www.strategyskills.com/Articles/Documents/Discovery

Hussey, D. (1998). Strategic management from theory to practice. Oxford: Butterworth-Heinemann.

Inyang, B. J. (2004). Corporate planning and policy: Concepts and applications. Calabar: Merb Business Centre.

Ireland, R. D., \& Hitt, M. A. (1992). Mission statements: Importance, challenge, and recommendations for development. Business Horizons, 35(3), 34-42. http://dx.doi.org/10.1016/0007-6813(92)90067-J

Klemm, M., Sanderson, S., \& Luffman, G. (1991). Mission statement: Selling corporate values to employees. Long Range, 24(3), 73-78. http://dx.doi.org/10.1016/0024-6301(91)90187-S

Kotler, P., Armstrong, G., Saunders, A. J., \& Wong, V. (2008). Principles of marketing (5th ed.). Pearson Education: Prentice-Hall.

Leonard, S. (2000). Walking the talk. Human Resource Magazine, 45(10), 256.

Macedo, P. (2009). Exploring the link between misson statements and organizational performance in non-profit healthcare organizations. Retrieved from http://www.marketingtrendscongress.com/CP/materiali/Fr/macedo Pinho.pdf

Medley, G. J. (1992). WWF UK creates a new mission. Long Range Planning, 25(2), 63-68. http://dx.doi.org/10.1016/0024-6301(92)90193-6

Mohammed, T. S., \& Mojtaba, N. L. (2013). Organization mission statement and organizational performance. Universal Journal of Management and Social Sciences, 3(8), 32-39.

Mullane, J. V. (2002). The mission statement is a strategic tool when used properly. Management Decision, 40(5), 448-455. http://dx.doi.org/10.1108/00251740210430461

Oghojafor, B. E. A., Olayemi, O. O., \& Okonji, P. S. (2011). Enhancing organization's performance through effective vision and mission. Chinese Business Review, 10, 1071-1075.

Pearce, J. A. (1982). The company mission as a strategic tool. Sloan Management Review, 23(3), 15-24.

Pearce, J. A., \& David, F. (1987). Corporate mission statements: The Bottom line. Academy of Management Executive, 1(2), 109-116. http://dx.doi.org/10.5465/AME.1987.4275821

Peyrefitte, J., \& David, F. R. (2006). A content analysis of the mission statement of United States firms in four industries. International Journal of Management, 23(2), 296-301.

Rarick, C. A., \& Vitton, J. (1995). Corporate strategy: Mission statement make cents. Journal of Business Strategy, 16(1), 11-13. http://dx.doi.org/10.1108/e6039673

Stone, M., \& Brush, C. (1996). Planning in ambiguous context: The dilemma of meeting needs for commitment and demands for legitimacy. Strategic Management Journal, 17(8), 633-652. http://dx.doi.org/10.1002/(SICI)1097-0266(199610)17:8<633::AID-SMJ837>3.0.CO;2-6

Sufi, T., \& Lyons, H. (2003). Mission statement exposed. International Journal of Contemporary Hospitality Management, 15(5), 255-262. http://dx.doi.org/10.1108/09596110310482173

Weiss, J., \& Piderit, S. (1999). The value of mission statements in public agencies. Journal of Public Administration Research and Theory, 9(2), 193-224. http://dx.doi.org/10.1093/oxfordjournals.jpart.a024408

William, L. S. (2008). The mission statement: A corporate reporting tool with a past, present and future. International Journal of Business Communication, 45(2), 94-119. http://dx.doi.org/10.1177/0021943607313989

Wilson, I. (1992). Realizing the power of strategic vision. Long Range Planning 25(5), 18-28. http://dx.doi.org/10.1016/0024-6301(92)90271-3

\section{Copyrights}

Copyright for this article is retained by the author(s), with first publication rights granted to the journal.

This is an open-access article distributed under the terms and conditions of the Creative Commons Attribution license (http://creativecommons.org/licenses/by/3.0/). 